Dhaka Univ. J. Biol. Sci. 19(2): 119-128, 2010 (July)

\title{
EFFECT OF MECHANICAL IMPEDANCE ON ROOT AND SHOOT GROWTH OF RICE AT TIME INTERVALS
}

\author{
A. H. M. Z. Ali* \\ Department of Plant \& Soil Science, University of Aberdeen, Aberdeen AB 24 3UU, U.K.
}

Key words: Mechanical impedance, Pattern of root growth, Time interval, Shoot growth, Rice

\begin{abstract}
In a phytotron chamber the effect of mechanical impedance on root and shoot growth of BR-29 variety of rice at different time intervals reaveled that length of the seminal axis and length of the longest leaf extended linearly in both unimpeded and impeded treatments. Diameter of roots increased in impeded treatment. The number of first order laterals also increased linearly with time in both unimpeded and impeded treatments. Although there were always significantly more laterals on the unimpeded root axes, lateral spacing does not show any tendency to change with time. Root growth rate was nearly half in impeded than in unimpeded treatment. The pattern of root length in unimpeded (UI) did not differ from that of the pattern in impeded (I) treatment as the ratios (I/UI) were more or less constant with time. The time of leaf appearance was delayed by one - two days and leaf growth period was shortened by one day in impeded than in unimpeded treatment. Leaf growth rates did not differ significantly between day and night time although night time growth rates were always slightly less than day time.
\end{abstract}

\section{Introduction}

Mechanical impedance and temperature affect both root and shoot growth of plants. Crop growth and yield are affected by mechanical impedance in five different ways ${ }^{(1)}$, i.e., structurally unstable soil that are subjected to rapid drying, hard layer, alternate wetting and drying, impedance which cause aeration problem and flowering in above ground portion. Effect of mechanical impedance on root and shoot growth of different grass species was found by Cook et al.(2)

Soil temperature often limits both system expansion and proliferation, particularly during growing season of crops.(3) Beyond an optimum range, both low and high temperatures have been found to reduce root and shoot growth of rice. ${ }^{(4)}$

The effect of mechanical impedance on growth rate is widely reported ${ }^{(5)}$ and steady growth rates that differ between impeding and unimpeding treatments have been found in Sorghum.(6) Kar et al.(7) reported an interactive effects of bulk density and day/night

*Present address: Department of Soil, Water and Environment, University of Dhaka, Dhaka-1000, Bangladesh 
temperature regime on root and shoot growth of rice grown in a submerged soil. However, in order to interpret the interactive effects of these factors, it is necessary to know the general trend of growth of rice with time in both unimpeded and impeded conditions, whether this variation is linear, or it differs before and after emergence or the pattern of root length variation with time differs between unimpeded (UI) and impeded (I) treatments. Therefore, this experiment was carried out to see the effect of mechanical impedance on root and shoot growth of rice at different time intervals.

\section{Materials and Methods}

Two different lengths of perspex cylinders were used: 300 and $200 \mathrm{~mm}$. Their internal diameter was $49 \mathrm{~mm}$. Metal mesh of $60 \mathrm{~mm}$ diameter was fitted to the base of each cylinder using adhesive tape. A small circle of general purpose J-cloth was fitted inside the metal mesh to prevent soil or sand from escaping through mesh.

There were (a) two levels of mechanical impedances (MI), unimpeded soil and impeded sand; (b) one cultivar (CV), BR-29; (c) one temperature regime, $27^{\circ} \mathrm{C}$; (d) seven growing periods (GP), 36 hours, 3, 5, 7, 9, 11 and 15 days. The cylinders were arranged in a completely randomised design inside the phytotron. Cylinders were re-randomised after every three days and the top of all of the cylinders were kept at roughly the same level.

The growth cylinders were packed with soil or sand uniformly mixed with nutrient solution following the packing styles developed for an unimpeded treatment with a penetration resistance (PR) of $0.05 \mathrm{MPa}$ (using soil) and an impeded treatment with a PR of 3.2 MPa (using sand). Penetration resistances were measured by needle penetrometer. Variation in mean penetration resistances in unimpeded and impeded treatments are shown in Fig. 1.
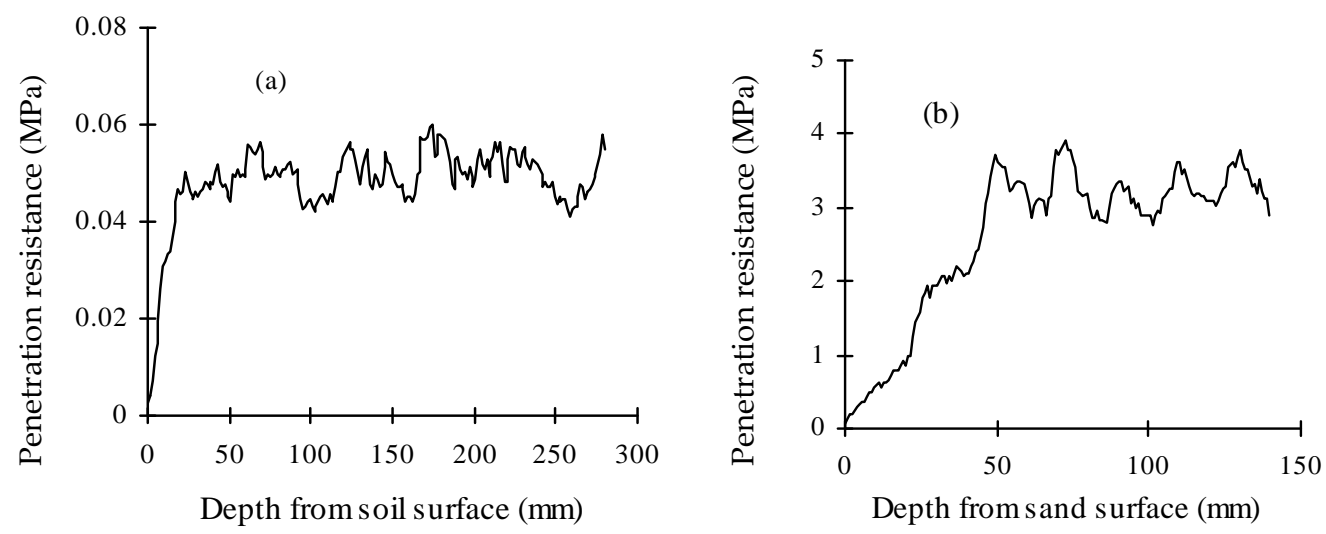

Fig. 1. Variation in mean penetration resistance (PR) with depth within a cylinder for (a) unimpeded treatment, $\mathrm{PR}=0.05 \mathrm{MPa}$ and $(\mathrm{b})$ impeded treatment, $\mathrm{PR}=3.2 \mathrm{MPa}$. 
Seeds of BR-29 variety of rice were germinated on wet filter paper. Preliminary germination trials were carried out to determine germination rates under these conditions. Thus the times when the seeds were placed on wet filter paper were chosen to ensure that each seed was at the same stage of germination when transferred to the packed growth cylinders.

Germinated seeds with a $4 \mathrm{~mm}$ long radicle were transplanted into the cylinders at a depth of $10 \mathrm{~mm}$ below the soil surface using green light between 10:00 - 11:00 hours. The lights in the phytotron were switched on at 11:00 hours and switched off at 23:00 hours.

The cylinders were weighed after packing and reweighed after 5 days interval and water was then added at $5 \mathrm{~cm}$ depth to restore the original weight of these cylinders using a hypodermic needle inserted at different points into the top of the cylinder. The aim was to rewet the zone of maximum depletion.

Soil temperature was recorded at 1 hour intervals throughout the experiment using thermistors connected to a data logger. Thermistors were placed at the centre of the cylinders at the depth of sowing by bending their wires at a $90^{\circ}, 25 \mathrm{~mm}$ from the end. The wire was secured in place with adhesive tape at the level of the thermistor and at the top of the cylinder. The remainder of the cylinder was packed according to the required treatment.

Cylinders were placed in a high light phytotron with irradiance ranging between 320 and $430 \mu \mathrm{mol} / \mathrm{s} / \mathrm{m}^{2}$ at plant height. Relative humidity was set to $70-80 \%$, and temperature at $27^{\circ} \mathrm{C}$. Air temperature inside the phytotron was also recorded with thermistors connected to the data logger.

At the time of harvesting, the growth cylinders were collected from the high light phytotron and submerged in a container full of water for one hour after removing the base of cylinders. When the soil became loose it fell freely down the cylinder as it was removed from the cylinder. The plants were then collected from the container placed in a Petri dish, and washed thoroughly with distilled water to remove soil or sand attached to the roots. The plants were temporarily kept in these Petri dishes full of water during measurement of root and shoot parameters.

The length of the seminal axis and root diameter $10 \mathrm{~mm}$ above the root tip were measured using digital vernier callipers $( \pm 0.01$. The number of first order laterals were counted under a large-field illuminated bench magnifier keeping the root system in a Petri dish. The distance between the first and the last lateral $\left(\mathrm{L}_{1}\right)$ was measured using a digital vernier callipers. Average lateral spacing (Ls) was calculated as given in the following equation ${ }^{(8)}$ : $\mathrm{Ls}=\mathrm{L}_{1} / \mathrm{n}-1$ (where $\mathrm{n}$ is the total number of laterals).

The length of the leaf was measured to $\pm 0.01 \mathrm{~mm}$ using digital vernier callipers. Length of leaves were measured at 12 hour intervals (at 11:00 and 23:00 hrs) for the 15 days growing period, but for the other growing periods only the longest leaf was measured at harvest time. The first day of appearance for leaf 1, 2, 3, 4, 5 and 6 was 
recorded by observing the plants at six hours interval for the 15 days growth period plants.

Statistical analysis was done using Minitab Statistical Software, release 10 Xtra. Significant differences between pairs of means were tested using the value of least significant difference (LSD).

\section{Results and Discussion}

Changes in phytotron temperature in the air and in the soil column during day and night time are shown in Fig. 2. Average day time temperatures in the air and the soil were $27.1 \pm 0.45$ and $34.1 \pm 1.3^{\circ} \mathrm{C}$, respectively and at night $26.3 \pm 0.16^{\circ} \mathrm{C}$ and $25.9 \pm$ $0.11^{\circ} \mathrm{C}$, respectively. Variation in temperatures between day and night were higher in the soil than in the air. Air temperature varied by only $0.80^{\circ} \mathrm{C}$, whereas soil temperature varied by $8.2^{\circ} \mathrm{C}$.

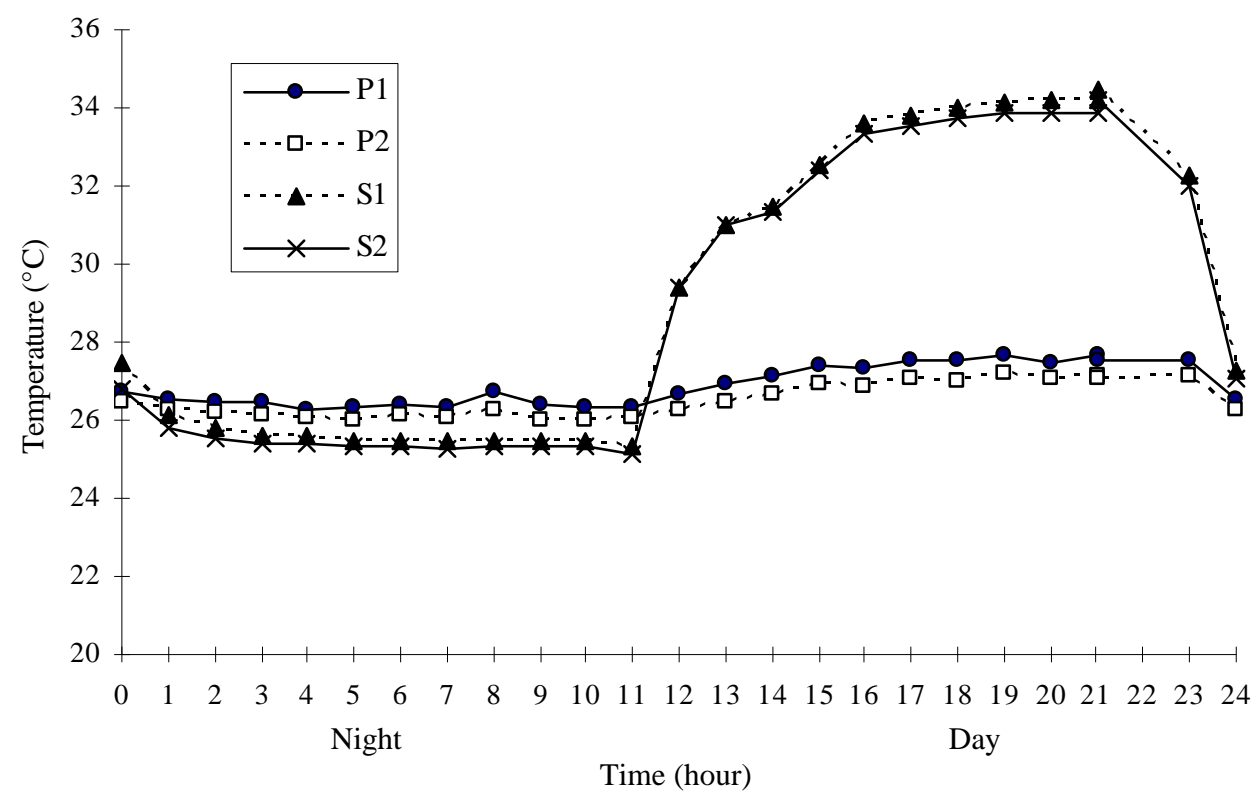

Fig. 2. Changes in the phytotron temperature in the air and the soil column during day and night time. P1, P2 and S1, S2 stands for the thermistors recording the air and the soil temperatures, respectively.

The length of the seminal axis and shoot length of the longest leaf of variety BR-29 at different time intervals are shown in Fig. 3. Root and shoot extended linearly in both unimpeded and impeded treatments. Growth rate was calculated by dividing root length by growth time. This gives an average root growth rate over the time interval (Fig. 4). Root growth rate was about half as much in the impeded than in the unimpeded 
treatment. Steady growth rates that differ between impeded and unimpeded treatments have also been found in cotton. ${ }^{(9)}$
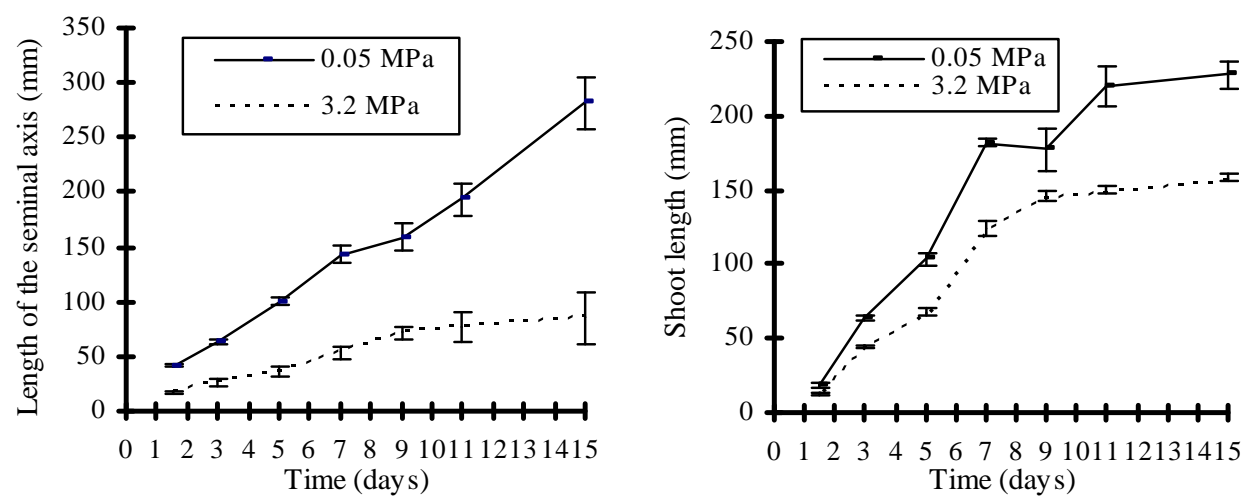

Fig. 3. Length of the seminal axis and shoot length of the longest leaf of BR-29 variety of rice at different time intervals 15 days after transplanting in unimpeded soil $(0.05 \mathrm{MPa})$ and impeded sand (3.2 MPa) treatments. Error bars represent $\pm 1 S E(n=6)$.

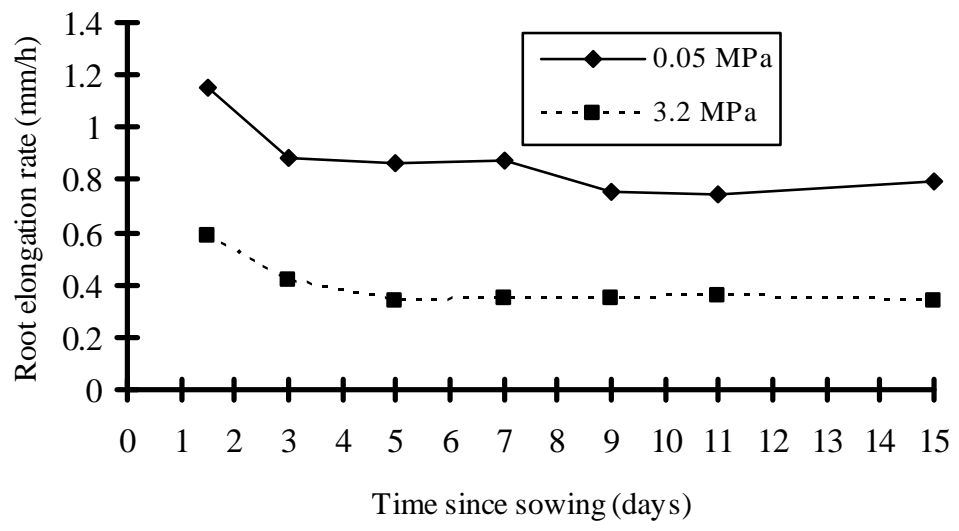

Fig. 4. Root elongation rate of BR-29 variety of rice at different time intervals grown in unimpeded soil $(0.05 \mathrm{MPa})$ and impeded sand $(3.2 \mathrm{MPa})$.

The number of first order laterals increased linearly with time in both unimpeded and impeded treatments (Fig. 5a). Although there were always significantly more laterals on the unimpeded root axes, lateral spacing does not show any tendency to change with time (Fig. 5b). Assuming that new laterals were not produced on older, branched part of the axis, this implies that laterals were produced at a steady rate. Hence, if they only emerge just behind the zone of extension ( and not elsewhere), then the spacing of laterals along the axis should be uniform, as was observed. There was no change in root diameter (10 mm behind the root tip) with time, but root diameter was significantly $(\mathrm{p}<$ $0.001)$ and considerably greater (1.7 times) in the impeded than in the unimpeded treatment (Fig. 5c). 


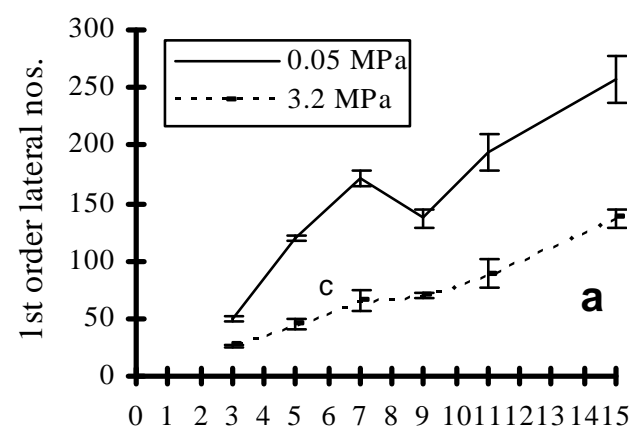

Time (days)
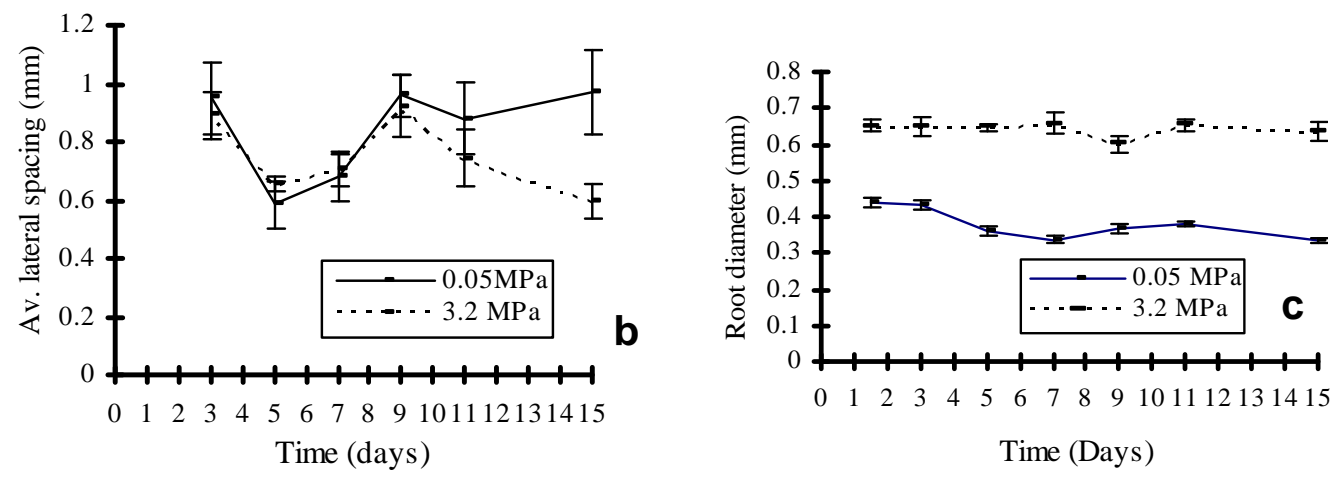

Fig. 5. Effects of unimpeded (0.05 MPa) soil and impeded sand (3.2 MPa) treatments on (a) 1st order lateral numbers, (b) av. lateral spacing and (c) root diameter of BR-29 variety of rice at different time intervals. Error bars represent \pm 1SE $(n=6)$.

Ratios between length of the seminal axis in impeded and unimpeded treatments at different time intervals did not differ significantly $(p>0.05)$ as shown in Table 1 . This implies that there were no significant $(p>0.05)$ changes in the pattern of root length variation with time between impeded and unimpeded treatments.

Table 1. Ratio between length of the seminal axis in impeded (I) and unimpeded (UI) treatments at different time intervals.

\begin{tabular}{lccccccc}
\hline Ratio & $36 \mathrm{~h}$ & $3 \mathrm{~d}$ & $5 \mathrm{~d}$ & $7 \mathrm{~d}$ & $9 \mathrm{~d}$ & $11 \mathrm{~d}$ & $15 \mathrm{~d}$ \\
\hline I/UI & 0.409 & 0.408 & 0.367 & 0.374 & 0.451 & 0.396 & 0.301 \\
\hline
\end{tabular}

$\mathrm{LSD}=0.169$ at $5 \%$.

Day of leaf appearance, duration of growth and mature leaf length for unimpeded and impeded treatments are shown in Fig. 6. Mature leaf lengths of leaf 1, 2, 3 and 4 were reduced by impedance to approximately $42,23,34$ and $62 \%$ of those in the unimpeding treatment (Fig. 6c). These results are similar to those found for both dicots and monocots 
in other studies on the effects of root impedance during the early growth periods. Blaikie and Mason ${ }^{(10)}$ grew T. repens stolon cuttings in cores of field soil at various penetration resistances and found that after 38 days of growth, plants in the soils with a high penetration resistance produced significantly fewer and smaller leaves. Beemster and Masle $^{(11)}$ found similar results for wheat (Triticum aestivum L.) where, at high penetration resistance lengths of leaf 1, 3 and 5 were decreased by 21, 16 and $27 \%$, respectively, compared to a low penetration resistance treatment in soil. They also found changes at
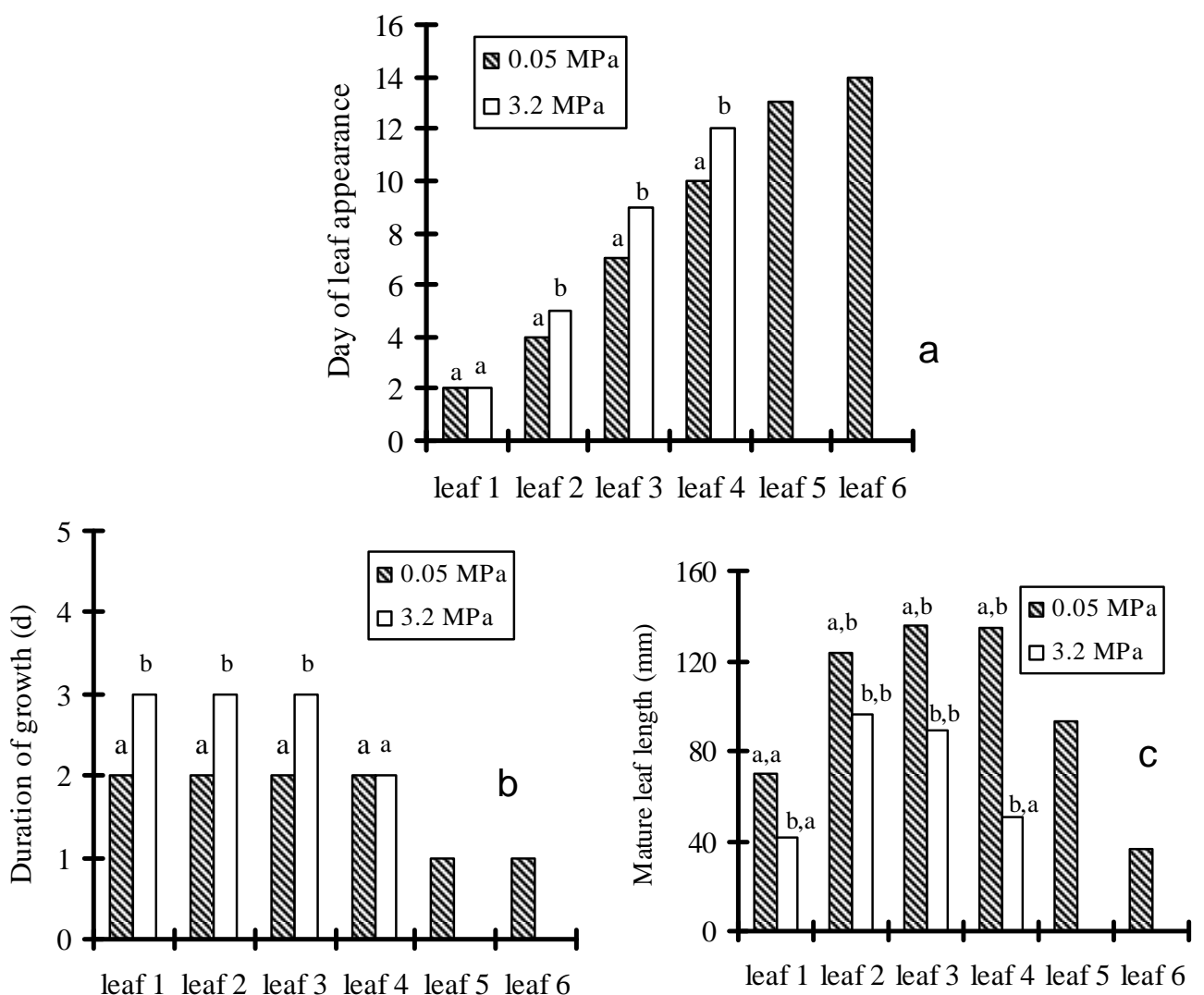

Fig. 6. Effects of unimpeded (0.05 MPa) soil and impeded sand (3.2 MPa) treatments on (a) day of leaf appearance, (b) duration of growth and (c) mature leaf length of BR-29 variety of rice 15 days after transplanting. Mean values that do not differ significantly share the same letter $(n=6)$. First letter compares between the treatments and 2nd letter compares between the leaves.

the cellular level in leaf 1, 3 and 5 in response to high penetration resistance (PR) where in leaf 1 epidermal cells became smaller and the number of cells in leaf 3 but not their lengths were significantly reduced. In leaf 5 both cell size and number were significantly reduced by high penetration resistance. They concluded that these differences in cell growth were due to impedance affecting leaves that were at different developmental 
stages (leaf 1 and leaf 3 started their development from the embryo, but leaf 5 developed on the seedlings).

The time of leaf appearance was delayed by $1-2$ days for leaf 2, 3 and 4 in the impeded compared to the unimpeded treatment and the leaf growth period was shortened by 1 day for leaf 1, 2 and 3 (Fig. 6a). As a result, leaf 5 and leaf 6 was appeared in unimpeded treatment. Cook et al.(2) also found that soil impedance to roots resulted in delays in leaf appearance by 1 - 2 days and caused a reduction in leaf relative growth rate in Lollium perenne. In a more detailed study where Masle ${ }^{(12)}$ grew wheat plants in cylindrical pots in homogeneously packed soil at different penetration resistances and also in pots with two soil layers (low penetration resistance over high penetration resistance). She found a delay in appearance of leaf 3 and 4 of seedlings in the uniform high penetration resistance soil compared to a control with a moderate penetration resistance. She also observed, in the two-layered (medium impedance (1.17) over a high impedance $(3.6 \mathrm{MPa}))$ pots, a lag between the roots experiencing a change in penetration resistance between these layers. This lag period was 7 - 10 days for leaf 3. Similarly, stomatal conductance did not decrease until 7 - 9 days after the first root tip had experienced high penetration resistance. In explaining this lag(12) concluded that leaf biological age was probably an important factor and that these results showed that leaf sensitivity to soil penetration resistance was mostly confined to the early stages of growth (i.e. up to the formation of the leaf intercalary meristem).

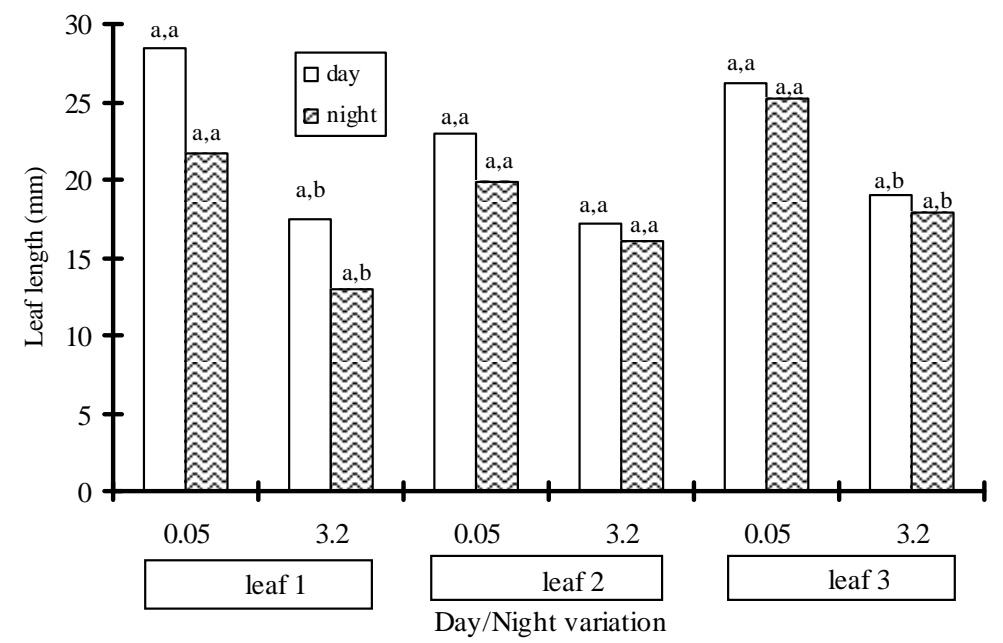

Fig. 7. Leaf length between day and night time of BR-29 variety of rice grown in unimpeded soil $(0.05 \mathrm{MPa})$ and impeded sand (3.2 $\mathrm{MPa})$ treatments. Leaf lengths that do not differ significantly $(p<0.05)$ share the same letter $(n=6)$. First letter compares between the treatments and second letter compares between day and night time for individual leaf. 
Young et al.(13) grew wheat and barley plants in a series of growth cell containing sand surrounded by a flexible impermeable membrane inside a rigid plastic tube with an adequate supply of nutrient and water. They increased the penetration resistance (PR) in the sand by applying an external confining pressure to the sand. By increasing the PR in the medium, they observed a reduction in leaf elongation rate within ten minutes when the applied pressure was increased to $3.38 \mathrm{MPa}$ compared to unimpeding cells at 0.14 $\mathrm{MPa}$. This result is in contrast with the results of ${ }^{12)}$ experiment. This may be due to the differences in the experimental procedures followed to give mechanical impedance to the root. A rapid increase in pressure to give more impedance could cause sudden changes in turgor pressure because the whole system will experience additional external pressure and not just the growing zones. This could then cause the observed rapid change in leaf growth, but does not necessarily reproduce a field situation.

There were no significant ( $p>0.05$ ) effects on leaf 1,2 and 3 lengths between day and night time in both impeding and unimpeding treatments (Fig. 7). Significant $(p<0.05)$ differences were found between unimpeding and impeding treatments in leaf 1 and 3 lengths in both day and night time. Yin et al.(14) found no significant effects of day and night time temperature on leaf appearance in rice, but significant effects on the rate of development to flowering and suggested that development processes occurring simultaneously during plant growth could have different sensitivities to day and night temperatures.

\section{Acknowledgements}

The author is grateful to his Ph.D. supervisor Dr. C.E. Mullins. He is also grateful to Mr. Inverarity, Inverarity Farms, Dundee for supply of soil.

\section{References}

1. Taylor, HM and GF Arkin 1981. Root zone modification: Fundamentals and Alternatives. In: Modifying the root environment to reduce crop stress, Arkin, G. F. et al. (ed.), pp. 9-11. The American society of Agricultural Engineers. Michigan, USA.

2. Cook A, CA Marriot, W Seel and CE Mullins 1996. Effects of soil mechanical impedance on root and shoot growth of Lollium perene L., Agrostis capillaris and Trifolium repens L. J. Exp. Bot. 47(301): 1075-1084.

3. Kaspar TC and WL Bland. 1992. Soil temperature and root growth. Soil Sci. 154(4): 290-299.

4. Dunbabin TD 1997. The effects of temperature and water potential on the germination of sorghum. Ph.D. Thesis. University of Aberdeen, U.K.

5. Bengough AG and CE Mullins 1990. Mechanical impedance to root growth: a review of experimental techniques and root growth resonses. J. Soil Sci. 41: 341-358.

6. Bhattacharyya AK and SK De Datta 1971. Effects of soil temperature regimes on growth characteristics, nutrition and grain yield of IR22 rice. Agron. J. 63: 443-449. 
7. Kar S, SB Varade, Subramanyam and BP Ghildyal 1976. Soil physical conditions affecting rice root growth. Bulk density and submerged soil temperature regime effects. Agron. J. 68: 23-26.

8. Tsegaye, $\mathrm{T}$ and CE Mullins 1994. Effect of mechanical impedance on root growth and morphology of two varieties of pea (Pisum sativum L.). New Phytol. 126: 707-713.

9. Nabi G 1998. The effects of soil physical factors on the germination and emergence of cotton. Ph.D. Thesis. University of Aberdeen, U.K.

10. Blaikie SJ and WK Mason 1993. Restriction to root growth limit the yield of shoots of irrigated white clover. Aust. J. Agril. Res. 44: 121-135.

11. Beemster GTS and J Malse 1996. Effects of soil resistance to root penetration on leaf expansion in wheat (Triticum aestivum L.): composition, number and size of epidermal cells in mature blades. J. of Experimental Botany. 47(304): 1651-1662.

12. Masle J 1998. Growth and stomatal responses of wheat seedlings to spatial and temporal variations in soil strength of bi-layered soils. J. Exp. Bot. 49(324): 1245-1257.

13. Young IM, K Montagu, J Conroy and AG Bengough 1997. Mechanical impedance of root growth directly reduces leaf elongation rates of cereals. New Phytology 135: 613-619.

14. Yin, X. and MJ Kropff 1996. The effects of temperature on leaf appearance in rice. Ann. Bot. 77: 215-221.

(Manuscript received on 14 October, 2009; revised on 17 December, 2009) 